\title{
Flexible Tunable Spectrum Sliced Microwave Photonic Filter Using Parallel Fabry-Pérot Filters and Fiber Bragg Grating
}

\author{
R.K. Jeyachitra ${ }^{1}$, Dr. (Mrs.) R. Sukanesh ${ }^{2}$ \\ 1. Assistant Professor, Department of Electronics and Communication Engineering, National Institute of \\ Technology (NIT), Thuvakudi, Tiruchirappalli, TamilNadu, India. Phone: +910431 2503320(Off.), +91 \\ 09443145540 (Mob), +91 04312459447(Res), Fax: 0431- \\ 2500133.Email:jeyachitra@nitt.edu,rkjcmano@yahoo.co.in,rkjcmano@gmail.com. \\ 2.Professor, Department of Electronics and Communication Engineering, Thiagarajar College of Engineering, \\ Madurai, Tamil Nadu, India.
}

\begin{abstract}
A simple and low-cost spectrum sliced microwave photonic filter with high tunability has been implemented. This is based on use of two Fabry-Pérot filters with same free spectral range connected in parallel but one filter with an external fiber delay. An extension of this configuration with Fiber Bragg Grating (FBG) as delay element is also demonstrated. This architecture overcomes the tuning difficulties of a single Fabry-Pérot filter employed as a slicing element. Flexible tunability, large overall free spectral range and high quality factor have been obtained with the proposed configuration owing to the use of fiber delay/FBG. Wide and step tuning has been achieved in the frequency range of 41.1GHz to $50.23 \mathrm{GHz}$ in steps of $2.28 \mathrm{GHz}$. The additional components are another Fabry-Pérot filter and fiber delay/FBG which makes the proposed architecture highly compact and costeffective. Most of the practical difficulties faced in use of optical fiber are eliminated using FBGs. The characteristics of proposed configuration with different applied delays using fiber and FBG were tabulated. An analysis of flexible tunable property of the filter was made in terms of length of fiber delay and grating length of FBG and the results were plotted. Also quality factor calculation of the proposed filter was discussed.
\end{abstract}

Index Terms - Fabry-Pérot (FP) filter, Fiber Bragg Grating, fiber delay, Free Spectral Range (FSR), Microwave photonics, Q-factor, spectrum slicing, tunability.

\section{INTRODUCTION}

Microwave photonics is today an innovative multidisciplinary and interdisciplinary field combining and transferring different technologies. Continued progress in photonic components and technology sustains great interest in this field and expanding acceptance of photonics for microwave systems. The many advantages of microwave fiber-optic communication links over conventional coaxial or waveguide links include reduced size, less weight, low cost and constant attenuation over the entire modulation frequency range. They have excellent reconfigurability, extremely wide bandwidth, low dispersion, high immunity to ElectroMagnetic Interference (EMI) and high information transfer 
capacity. They are suitable for a number of applications such as personal communication networks, millimeter (mm)-wave radio LANs, antenna remoting, broadband video distribution networks and signal distribution for phased array antennas. With these new applications there are increasing requirements for high performance devices for microwave and mm-wave systems where they are used due to broadband low-loss and high-speed transmission capability of optical fibers. There is a great scope for developing $40 \mathrm{GHz}$ broadband cellular network technologies in the near term and there is an increased interest in the possibilities of using the $60 \mathrm{GHz}$ and $70 \mathrm{GHz}$ bands, with their excellent frequency reuse, for broadband pico-cellular operations. The breakthrough in the design and demonstration of several ultra broadband photonic components has paved the way for wideband and highly efficient optoelectronic converters used as important building blocks for microwave-optical links [1]. However, there is the difficulty of attaining the reconfigured band pass transfer function of any filter with the traditional microstrip or waveguide Radio Frequency (RF) technologies. This difficulty can be overcome by external on-line measures in spectrum sliced microwave photonic filters.

Several techniques have been deployed for spectrum slicing in microwave photonic filters [2] since 1996 up to 2008 and highly integrated and user-friendly software applications have also been developed [3] that enable the Computer-Aided Design (CAD) and simulation of these techniques. The fiber optic microwave and mm-wave filter demonstrated in the year 1996 is the first filter with highest number of filter taps, greater sidelobe suppression and fine, clear spectral slices [4].A transmissive type FP filter with low spectral period was used to realize sub nanometer resolved optical sampling with the reported FSR of $4.6 \mathrm{GHz}$.

Since an FP filter is a fixed optical filter, there are serious limitations of tunability and weight adjustment. The flexibility of this photonic microwave filter is very low and needs specially designed FP filter. It is difficult to achieve wide range of filter tunability since this requires the change of the slicing filter FSR. To tune the filter response, the Fabry-Pérot cavity has to be greatly changed to modify the FSR and the cavity has to be finely adjusted using optical switches and piezoelectrics [6]. This severely limits the practical feasibility of the architecture.

We propose an extension to the approach used in [4], [5] in order to obtain enhanced and widerange tunability. This proposed architecture uses two FP filters in parallel but one of them with an adjustable fiber delay or FBG which gives flexible tunability in the range of $40 \mathrm{GHz}$ to $50 \mathrm{GHz}$. Bragg gratings are attractive as sampling elements because the tap weights can be controlled via the grating reflectivity, the sampling time can be controlled via the grating spacing, and the interaction wavelength can be controlled via the grating pitch [7]. Second section explains the topology of the filter and analyzes the operation of the individual components. Section three discusses the simulated results obtained using the proposed architecture. Finally, we present the conclusions. 


\section{FILTER TOPOLOGY AND OPERATION}

The general layout of the filter is shown in Fig. 1. The optical source is a low-cost, broadband Amplified Spontaneous Emission (ASE) spectrum which is obtained from a pumped Erbium Doped Fiber Amplifier (EDFA). The ASE signal level however is usually very small and requires further amplification in order to overcome the losses introduced by the remaining components of the filter. The optical power from the source is split and spectrally sliced by use of two multiwavelength FP filters connected in parallel, one with an adjustable delay implemented using either optical fiber or FBG, to obtain the equivalent set of spectrally equispaced optical sources. The output light from the parallel combination FP filters is combined and subsequently modulated by RF signal by means of an external modulator and fed to an optical dispersive element providing a linear group delay characteristic. The output signal from the dispersive element is fed to a photodetector and subsequent RF circuit.

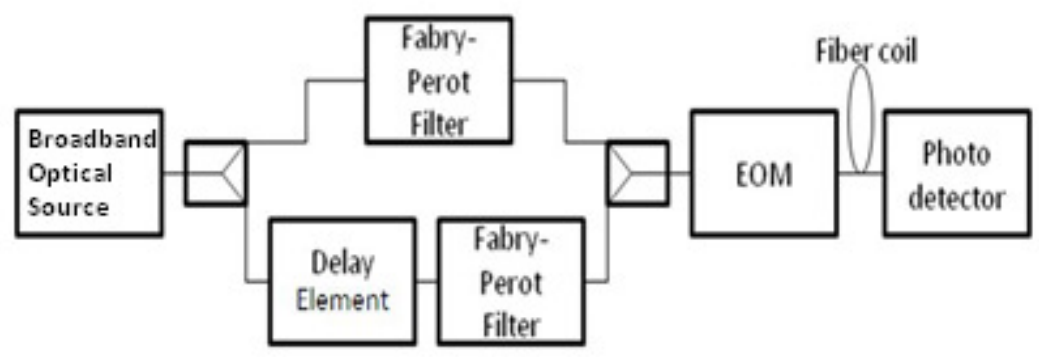

Fig.1. General Layout of the proposed configuration.

\section{THEORY}

When Single-Sideband (SSB) modulation is employed for the RF signal and a single FP filter is used, the RF transfer function of the filter [5] is given as

$$
\left|\mathrm{H}_{\mathrm{RF}}(\Omega)\right|=\mathrm{R}\left|\sum_{\mathrm{k}=1}^{\mathrm{N}} \mathrm{P}_{\mathrm{k}} \mathrm{e}^{-\mathrm{j}[\Omega(\mathrm{k}-1) \Delta \tau}\right|
$$

where $\mathrm{P}_{\mathrm{k}}$ represents the output power from the $\mathrm{k}^{\text {th }}$ slice of the broadband source, $\mathrm{R}$ is the receiver responsivity, $\Omega$ is the RF frequency, and $\Delta \tau$ represents the incremental differential delay experienced by two adjacent spectral slices of the broadband source is given by

$$
\Delta \tau=\operatorname{DL} \Delta \lambda
$$

where $\mathrm{D}(\mathrm{ps} / \mathrm{km} . \mathrm{nm})$ is dispersion parameter, $\mathrm{L}(\mathrm{m})$ is the length of fiber and $\Delta \lambda(\mathrm{nm})$ is wavelength spacing. Equation (1) represents the spectral response of a Finite Impulse Response (FIR) filter where the number $\mathrm{N}$ of signal samples is equal to the number of significant spectral slices generated by the optical filter. 
When two FP filters are used in parallel, the overall transfer function is given as

$$
\begin{gathered}
\left|\mathrm{H}_{\text {overall }}(\Omega)\right|=\left|\mathrm{H}_{1}(\Omega)+\mathrm{H}_{2}(\Omega)\right| \\
=\mathrm{R}\left|\sum_{\mathrm{k}=1}^{\mathrm{N}} \mathrm{P}_{\mathrm{k}} \mathrm{e}^{-\mathrm{j}\left[\Omega(\mathrm{k}-1)\left(\Delta \tau_{1}\right)\right]}+\sum_{\mathrm{k}=1}^{\mathrm{N}} \mathrm{P}_{\mathrm{k}} \mathrm{e}^{-\mathrm{j}\left[\Omega(\mathrm{k}-1)\left(\Delta \tau_{2}+\tau\right)\right]}\right|
\end{gathered}
$$

where $\tau$ represents the time delay offered by the fiber or FBG.

When FBG is used as a delay element [8],

$$
\mathrm{T}_{\mathrm{r}}=\mathrm{D}_{\mathrm{g}} \mathrm{L}_{\mathrm{g}} \Delta \lambda_{\mathrm{t}}=2 \overline{\mathrm{n}} \mathrm{L}_{\mathrm{g}} / \mathrm{C}
$$

where $T_{r}$ is the round-trip time for a grating of length $L_{g}, \Delta \lambda_{t}$ is the total shift in bragg wavelength, $D_{g}$ is the dispersion parameter, $\bar{n}$ is the average refractive index and $\mathrm{c}$ is velocity of light in the fiber.

\section{NUMERICAL RESULTS AND DISCUSSION}

The MATLAB simulation platform was used to demonstrate the operation of the proposed microwave photonic filter shown in Fig. 2. To obtain sharply apodised sliced spectrum with $\mathrm{N}=34$ taps, only a $9 \mathrm{~nm}$ portion (centered at $1531.8 \mathrm{~nm}$, the wavelength corresponding to the ASE maximum of EDFA1) of the ASE output from EDFA1, was divided by means of a 1x2 splitter and fed to the FP filters connected in parallel. The output optical spectrum of broadband optical source was obtained using OPTSIM toolkit. The output from the FP filters was added using a 2x1 optical coupler. The optical dispersive element was implemented by means of a coil of $46 \mathrm{~km}$ of singlemode standard optical fiber with dispersion parameter $\mathrm{D}=17 \mathrm{ps} / \mathrm{km} . \mathrm{nm}$ and wavelength spacing of $0.28 \mathrm{~nm}$, although a linearly chirped fiber grating could also be employed. The output signal is amplified by EDFA2 and fed to a photodetector.

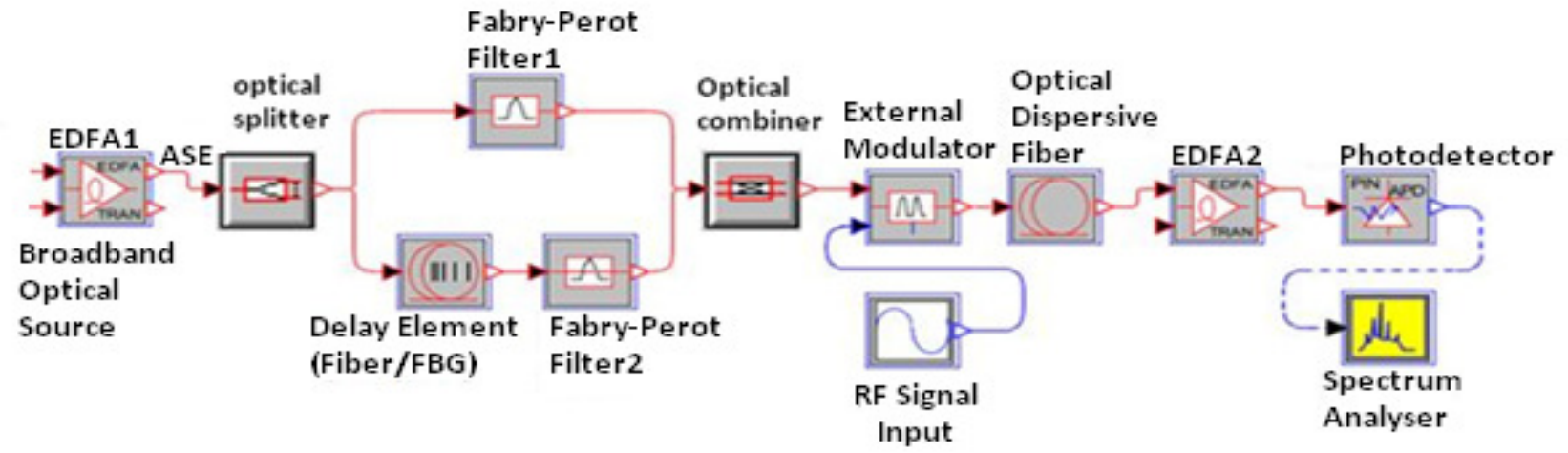

Fig.2. Proposed topology of the spectrum sliced microwave photonic filter. 


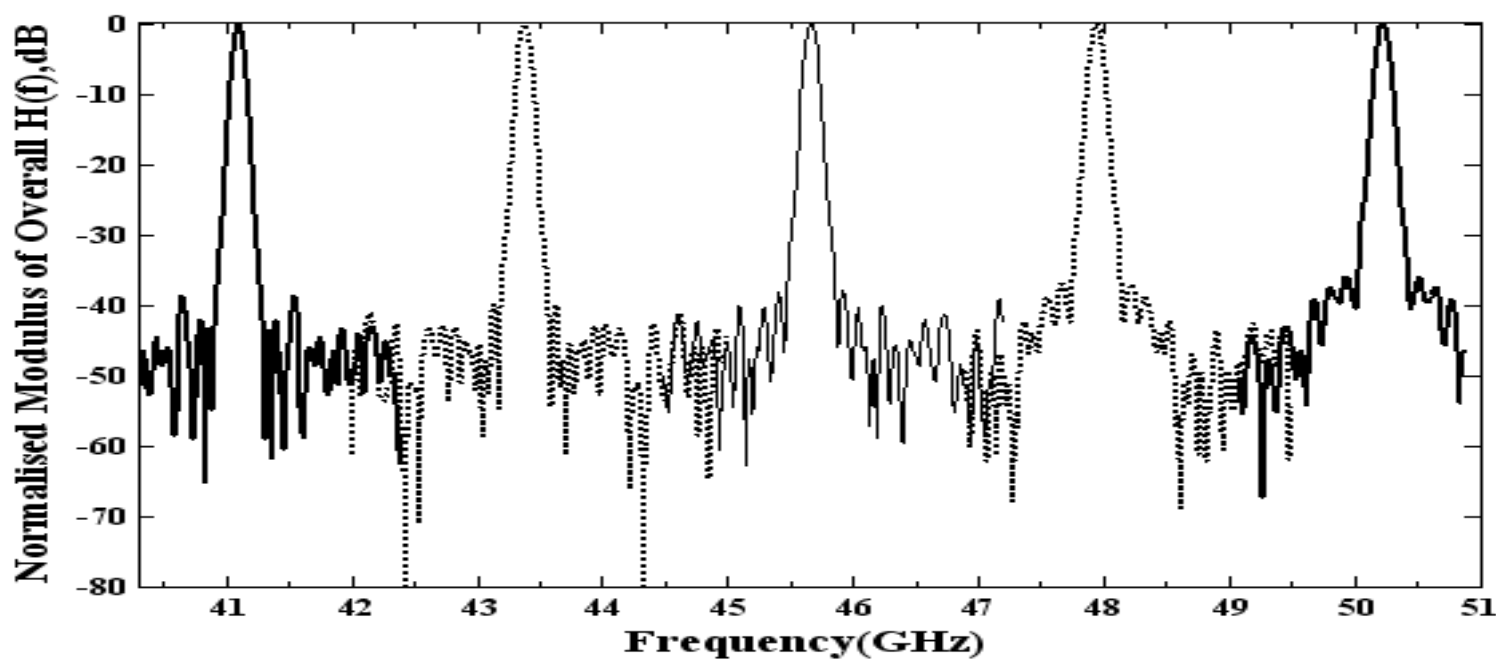

Fig. 3. Frequency characteristics of proposed configuration with the FP filter having same FSR with delay of 20, 42, 66, 92 and $122 \mathrm{ps}$.

When two FP filters of same incremental differential delay $\Delta \tau_{1}$ and $\Delta \tau_{2}$ of 219 ps were used in the configuration but without fiber delay, the response of the filter was not different from the response of a single filter as obtained in [4].Then the two FP filters of same incremental differential delays $\Delta \tau_{1}$ and $\Delta \tau_{2}$ of $438 \mathrm{ps}(=17 \mathrm{ps} / \mathrm{km} . \mathrm{nm} \times 92 \mathrm{~km} \times 0.28 \mathrm{~nm})$ were used in the proposed configuration along with fiber delay. The fiber delay times $\tau=122 \mathrm{ps}, 92 \mathrm{ps}, 66 \mathrm{ps}, 42 \mathrm{ps}$ and $20 \mathrm{ps}$ were offered by using singlemode standard fiber and adjusting its length to $25.6 \mathrm{~km}, 19.3 \mathrm{~km}, 13.9 \mathrm{~km}, 8.8 \mathrm{~km}$ and $4.2 \mathrm{~km}$ respectively. This configuration provides high FSR and flexible tuning range from $40 \mathrm{GHz}$ to $50 \mathrm{GHz}$. The FSR of this filter could be varied from $41.1 \mathrm{GHz}$ to $50.23 \mathrm{GHz}$ in steps of $2.28 \mathrm{GHz}$. The filter frequency responses are shown in Fig. 3 obtained using (4) with the response of each configuration represented in a different trace, and other characteristics of this filter are mentioned in Table. I.

The delay times $\tau=122 \mathrm{ps}, 92 \mathrm{ps}, 66 \mathrm{ps}, 42 \mathrm{ps}$ and $20 \mathrm{ps}$ were then offered by using FBG taking average refractive index $\bar{n}=1.447$ and $c=299792458 \mathrm{~m} / \mathrm{s}$. Using (5) the grating length $\mathrm{L}_{\mathrm{g}}$ was adjusted to $12.613 \mathrm{~mm}, 9.559 \mathrm{~mm}, 6.811 \mathrm{~mm}, 4.324 \mathrm{~mm}$ and $2.064 \mathrm{~mm}$ and the results are given in Table. I. The same results as shown in Fig. 3. were obtained and are tabulated in Table. I. The required lengths of fiber delay were compared with required grating length. Thus FBGs of these grating lengths form effective substitutes for optical fiber as delay elements. There is no need to manually change the fiber length to obtain flexible tunability as in case of FBG is used as delay element. Also, the grating length required of FBG is very small in the order of millimeters compared to the length of fiber.

When no delay is given by fiber, the overall FSR is the frequency where a multiple of FSR of one filter is "sufficiently equal" to a multiple of FSR of the second filter. It is the first resonant frequency where the output powers of the filters sum up to give a total power of $-3 \mathrm{~dB}$ or more. Very high FSR is obtained when the FSR of the two filters differ very slightly (but usually with a delay time difference of around 10ps). The overall system loss of the architecture is compensated by the 
use of EDFA2.From Table I. the required grating length is very small and is in the order of millimeter to obtain high FSR with step tunability.

TABLE I. COMPARISON TABLE OF CHARACTERISTICS OF

PROPOSED CONFIGURATION WITH DIFFERENT APPLIED DELAYS USING FIBER AND FBG

\begin{tabular}{|c|c|c|c|c|c|c|}
\hline \multirow[t]{2}{*}{ S.No. } & \multirow[t]{2}{*}{ Fiber Delay $\tau(\mathrm{ps})$} & \multicolumn{2}{|c|}{ Required Length } & \multirow{2}{*}{$\begin{array}{c}\text { Overall } \\
\text { FSR } \\
\text { (GHz) }\end{array}$} & \multirow{2}{*}{$\begin{array}{c}\text { 3dB BW } \\
\text { (MHz) }\end{array}$} & \multirow{2}{*}{$\begin{array}{l}\text { Quality } \\
\text { Factor }\end{array}$} \\
\hline & & $\begin{array}{c}\text { Fiber delay } \\
(\mathbf{k m})\end{array}$ & $\begin{array}{c}\text { Grating } \mathbf{L}_{\mathrm{g}} \\
(\mathrm{mm})\end{array}$ & & & \\
\hline 1. & 20 & 4.2 & 2.064 & 50.23 & 90 & 558 \\
\hline 2. & 42 & 8.8 & 4.324 & 47.94 & 100 & 480 \\
\hline 3. & 66 & 13.9 & 6.811 & 45.66 & 90 & 507 \\
\hline 4. & 92 & 19.3 & 9.559 & 43.38 & 90 & 482 \\
\hline 5. & 122 & 25.6 & 12.613 & 41.1 & 80 & 514 \\
\hline
\end{tabular}

\section{A. Q-Factor Calculation}

The Q-factor of the overall filter is given as [9]

$$
\text { Q-factor }=(\text { Overall FSR }) /(3 \mathrm{~dB} \text { bandwidth })
$$

Fig.4 shows the offset response of the filter at $50.23 \mathrm{GHz}$ for the final tunable resonant peak. The overall FSR of $50.23 \mathrm{GHz}$ and a $3 \mathrm{~dB}$ bandwidth of $90 \mathrm{MHz}\left(\mathrm{f}_{1} \sim \mathrm{f}_{2}=50.18 \sim 50.27 \mathrm{GHz}=90 \mathrm{MHz}\right)$ were measured from Fig. 4. Using (6) the Q-factor of the filter at $50.23 \mathrm{GHz}$ was calculated and it is approximately of 558.In similar way, the Q-factor of the other resonant peaks were measured individually.

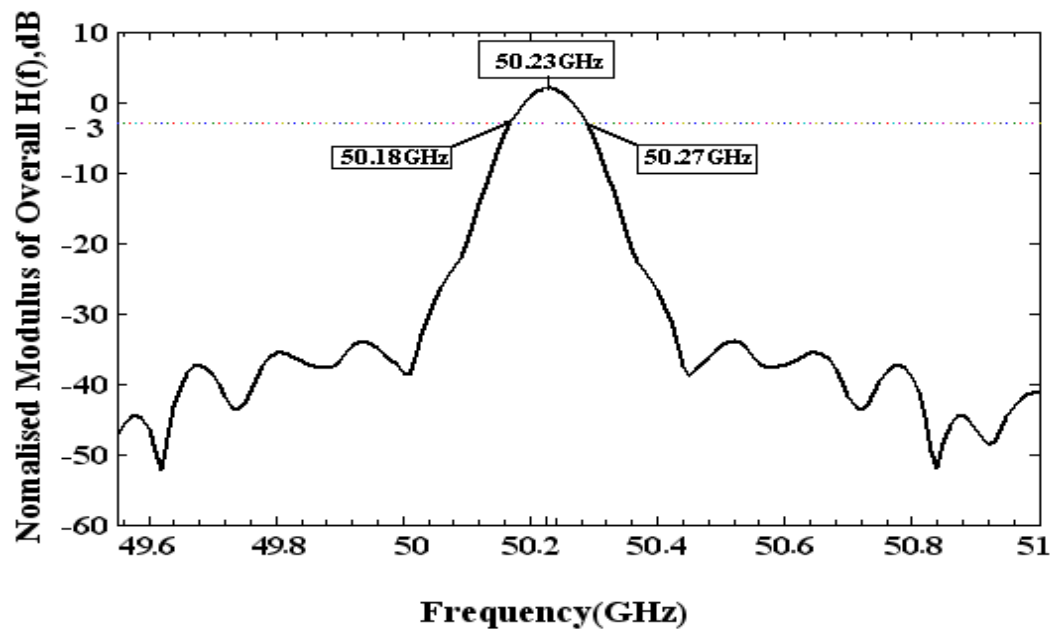

Fig. 4. Offset response of the filter at $50.23 \mathrm{GHz}$. 


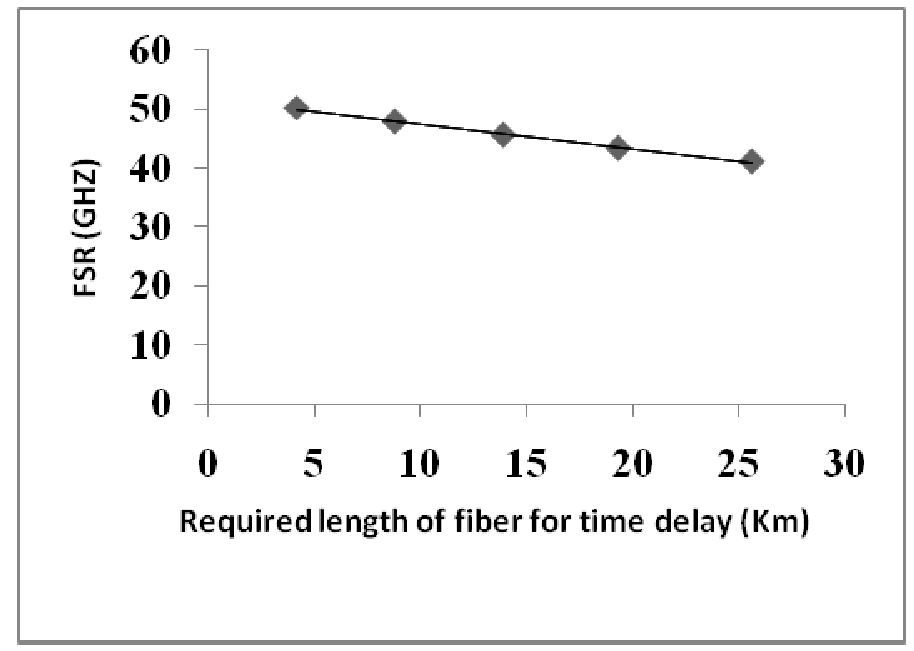

Fig. 5. FSR as a function of length of Fiber delay.

Fig.5 gives FSR as a function of length of fiber delay. The step tunability of the filter was achieved by adjusting length of fiber delay from $25.6 \mathrm{~km}, 19.3 \mathrm{~km}, 13.9 \mathrm{~km}, 8.8 \mathrm{~km}$ and $4.2 \mathrm{~km}$ to vary the FSR from $41.1 \mathrm{GHz}$ to $50.23 \mathrm{GHz}$ in steps of $2.28 \mathrm{GHz}$ respectively. Fig. 6 gives FSR as a function of grating length. The same results as shown in Fig.3. were obtained using FBG with reduced grating length. The delay times $\tau=122 \mathrm{ps}, 92 \mathrm{ps}, 66 \mathrm{ps}, 42 \mathrm{ps}$ and $20 \mathrm{ps}$ were offered by using FBG with the grating length $\mathrm{L}_{\mathrm{g}}$ of $12.613 \mathrm{~mm}, 9.559 \mathrm{~mm}, 6.811 \mathrm{~mm}, 4.324 \mathrm{~mm}$ and $2.064 \mathrm{~mm}$ respectively. Most of the practical difficulties faced in use of optical fiber are eliminated using FBGs. This makes the proposed architecture highly compact and cost-effective.

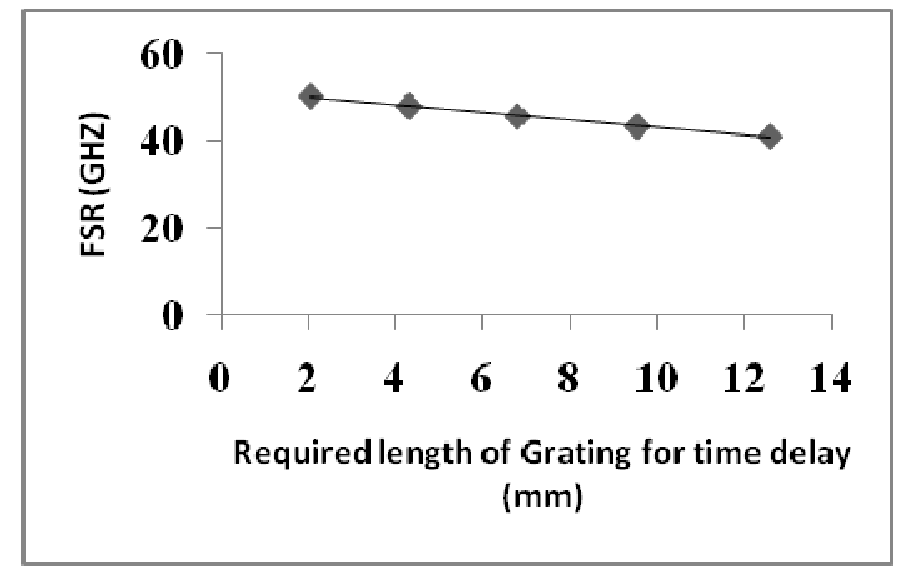

Fig. 6. FSR as a function of Grating length.

\section{CONCLUSION}

We achieved flexible tunability for applications in the frequency range of 40 to $50 \mathrm{GHz}$ by employing two FP filters of same FSR of $2.28 \mathrm{GHz}$ (corresponding to differential incremental delay of 
438ps) in parallel configuration, with one of them connected to variable optical fiber delay or FBG. This flexible tunability has been achieved by the use of the external delay element. The delay could be varied as $\tau=122,92,66,42$ and 20 ps to vary FSR discretely from $41.1 \mathrm{GHz}$ to $50.23 \mathrm{GHz}$ in steps of 2.28GHz. The results obtained are same for either optical fiber or FBG as delay element. Using FBGs, there is no need to manually change the fiber length to obtain flexible tunability. Also, the grating length required of FBG is very small compared to the length of fiber. The flexible tunable property of the filter was analyzed in terms of length of fiber delay and grating length of FBG and the results were plotted. The Q-factor of the proposed filter was measured. This makes the system compact and costeffective.

\section{ACKNOWLEDGMENT}

The authors gratefully acknowledge the wonderful suggestions and greatly useful directions by Prof. Arokiaswami Alphones of Nanyang Technological University (NTU), Singapore.

\section{REFERENCES}

[1] Chi H. Lee, editor, Microwave Photonics, CRC Press, Taylor \& Francis Group, 2007,pg 26.

[2] R. Sukanesh, R.K.Jeyachitra, P. Gautham, A. Raja and Shailesh Ajmera, "Investigation of the techniques deployed in spectrum slicing for microwave photonic filters," in IEEE Proc. Int. Conf. Computation, Commun. Networking (ICCCN) 2008, pp. 1-6, Dec.2008.

[3] R. Sukanesh, R.K.Jeyachitra, Shailesh Ajmera, K.Avinash, S.Manochandar, "Optical CAD tools for microwave photonic filters," Proc. Int. Conf. Mech. and Elect. Eng. (ICMEE) 2009, pp 93-98, Jul. 2009 and indexed in eProc. in World Scientific Press.

[4] J. Capmany, D. Pastor, B. Ortega, "Fiber optic microwave and millimeter-wave filter with high density sampling and very high sidelobe suppression using sub nanometer optical spectrum slicing," Electron. Lett, vol. 35, no. 6, pp. 494496, Mar.1999.

[5] R.K.Jeyachitra, R.Sukanesh and Shailesh Ajmera," Flexible Tunable Spectrum Sliced Microwave Photonic Filter Using Parallel Fabry-Pérot Filters and Fiber Delay", Proc. of IEEE-Asia Pacific Microwave Conference(APMC2009), pp481483, Dec.2009.

[6] Borja Vidal, Miguel A. Piqueras, Juan L. Corral, Javier Martí, "Tunable photonic microwave filter based on two parallel Fabry-Pérot filters." Proc.Int. Topical Meeting on Microwave Photonics, Oct. 2005, pp. 205-208.

[7] Kenneth O. Hill, Gerald Meltz, "Fiber Bragg Grating Technology Fundamentals and Overview", J. Lightw. Technol., vol. 15, no. 8, pp.1263-1276, Aug. 1997.

[8] Govind P. Agarwal, Author, Applications of Nonlinear Fiber Optics, Academic Press, Elsevier, 2006, pg 289.

[9] Lina ZHOU, Xinliang ZHANG, Enuming XU, "Q value analysis of microwave photonic filters", Front. Optoelectron. China.vol. 2, no. 3, pp. 269-278, February 2009.

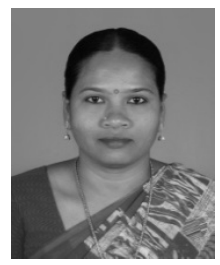

R. K. Jeyachitra received her B.E. degree in Electronics and Communication Engineering, M.E. in Microwave and Optical Engineering from Madurai Kamaraj University, Madurai in 1995 and 1997 respectively. She is currently pursuing research in microwave photonics. From 1998 to 2004 she worked as lecturer and from 2004-2007 as assistant professor at J.J. College of Engineering, Trichy. Now she is working as Assistant Professor in the department of ECE, National Institute of Technology, Trichy. Her research interests are microwave/ millimeter-wave photonics, Radio-over-Fiber (ROF) systems and Photonic Crystal Fibers (PCF). She is a life member of IE, IETE, ISTE and Member in OSA and SPIE.

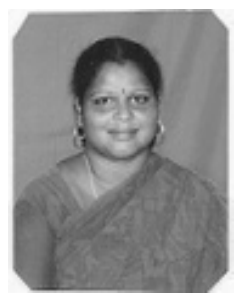

Dr. (Mrs.) R. Sukanesh, senior professor in Biomedical Engineering received her Bachelor's Degree B.E. (ECE) from Government College of Technology, Coimbatore in 1982. She obtained her M.E. degree (Communication Systems) from P.S.G. Technology, Coimbatore in 1985 and Ph.D. in Bio Medical Engineering from Madurai Kamaraj University, Madurai in 1999. Since 1985 she is working as a faculty in the department of ECE at Thiagarajar College of Engineering, Madurai and presently she is 
a professor in ECE and head of the Medical Electronics Division in the same college. Her main research areas include biomedical instrumentation, neural networks, bio-signal processing and mobile communication. She is guiding twelve Ph.D. thesis in the mentioned areas. She has published 30 papers in referred journals and also published around 80 papers in international and national conferences conducted both in India and aboard. She has delivered a number of invited lectures in various universities. She has a diploma in Higher Learning and has co-authored a book on Gandhian thoughts. She is reviewer for International Journal of Biomedical Sciences and International Journal of Signal Processing. She is editorial member for Journal of Engineering students. She contributed a chapter titled, "Impact of information technology in business" in the book, "Future organization strategies and business," edited by Professor Biswajeet Pattanayak. She is the recipient of the outstanding paper award at the $12^{\text {th }}$ International conference on Biomedical Engineering at Suntec city, Singapore in the year 2005. She is also the recipient of The President of India's Prize (English) 2006, The Jawaharlal Nehru Memorial prize-2006 and Woman engineer award from IE (India). She is a fellow of Institution of Engineers (India). She is a life member of Biomedical society of India, Indian Association of Biomedical Scientist and ISTE. 